\title{
Better ride for freight
}

\author{
R. A. Hassan \& K. McManus \\ Swinburne University of Technology, Australia
}

\begin{abstract}
In Australia, the heavy freight industry has complained for many years that using the International Roughness Index (IRI) for measuring road roughness does not address their rideability problems. Road surface irregularities with different lengths and amplitudes excite several vibration modes of the truck body with different frequencies and magnitudes. The resulting vertical, lateral, longitudinal and rotational motions detract from drivers' comfort and their perceptions of pavement ride quality. The measure that serves to highlight road sections providing poor ride quality to the freight industry needs to be capable of capturing all or the dominant of these motions. A new profile-based roughness index denoted Heavy Articulated Truck Index (HATI) has been developed to highlight such sections. In this paper a brief description is provided of HATI development and its effectiveness in identifying sections providing poor ride quality for heavy transport operators, compared to the IRI. The main objective of this paper is to report on the effects of subgrade soil reactivity on HATI values and the effectiveness of HATI as a predictor of pavement damage due to dynamic wheel loads.
\end{abstract}

Keywords: ride quality, heavy vehicles, dynamic wheel loads, expansive soil.

\section{Introduction}

Most Australian State Road Authorities (SRAs) use the International Roughness Index (IRI) as a measure to trigger pavement rehabilitation programs to improve ride quality and reduce road user costs. A number of studies [1-5] have indicated that the IRI is not suitable for characterising pavement ride quality for heavy vehicle occupants. This was confirmed through anecdotal instances reported by heavy transport operators to staff of SRAs, where the drivers complained about the rideability of road sections with IRI values much lower than the intervention levels. 
Road surface irregularities with different lengths and amplitudes excite several vibration modes of the truck body with different frequencies and magnitudes. These modes result in vertical motions due to excitation of body bounce, body pitch and axle hop modes. They also result in translational longitudinal (fore/aft) motion due to excitation of body pitch and frame bending and rotational motion due to body pitch. These modes occur at frequencies between 1.5 and $10 \mathrm{~Hz}$. Another vibration mode that affects truck ride is body roll, which occurs at frequencies below $1 \mathrm{~Hz}$ and results in translational sideways and rotational motions. These motions affect the comfort of heavy vehicle occupants and their perceptions of ride since the most effective excitation frequency of the human body for vertical vibration lies between 4 and $10 \mathrm{~Hz}$ and $0.5-2 \mathrm{~Hz}$ for longitudinal and lateral vibrations [6] with higher sensitivity to the first.

Ideally, a truck ride roughness index should capture all/most of these motions. However, the findings of surveys of whole body vibration exposure levels experienced by Australian heavy vehicle drivers indicated that weighted vertical vibrations were the dominant ones [3, 7]. Further, Hassan [3] noted that even with the filtering provided by an air bag-suspended seat in a one-year old primemover semi-trailer combination unit, the highest measured vertical accelerations occurred in the range of 1 to $4 \mathrm{~Hz}$. These results indicate that road input in the high frequency range (axle hop mode) is being successfully attenuated by vehicle design. This implies that roughness measures that characterise vertical vibrations in this frequency range could also be reasonable indicators of truck ride.

To address this problem, a research project, sponsored by VicRoads (SRA of Victoria/Australia), was initiated to develop a ride index to highlight pavement sections providing poor ride quality for the freight industry. This paper provides a brief description of the development of a profile-based ride index for heavy vehicles denoted Heavy Articulated Truck Index (HATI). Detailed description of HATI development can be found in Hassan et al. [8]. The main objective of this paper is to report on the effects of subgrade soil reactivity on HATI values and the effectiveness of HATI as a predictor of pavement damage due to dynamic wheel loads.

\section{What is HATI?}

HATI is a profile-based index for identifying pavement sections providing poor ride quality for transport operators travelling in heavy articulated trucks which are responsible for $80 \%$ of the Australian road freight transport task. HATI is a time-domain index which makes it suitable for use in pavement management at network level. It can be easily calculated using the same program/tool used for calculating the IRI. HATI of a road section is determined by processing the longitudinal surface profile of the section through a quarter truck model (QTM) with the properties shown in table 1 . The frequency response for HATI QTM is shown in fig. 1. The properties and frequency response of HATI QTM are based on those of a QTM described in Austroads [1] for a driver/seat/truck model but its frequency response was determined by excluding the effect of the driver/seat filter. 
Table 1: $\quad$ Parameters of QTM.

\begin{tabular}{|c|c|}
\hline Travel speed & $100 \mathrm{~km} / \mathrm{hr}=27.7777 \mathrm{~m} / \mathrm{s}$ \\
\hline $\mathrm{Ms}=$ Sprung mass & 1 \\
\hline $\mathrm{Ks} / \mathrm{Ms}=$ suspension stiffness & $250 \mathrm{~s}^{-2}$ \\
\hline $\mathrm{C}_{\mathrm{s}} / \mathrm{Ms}=$ suspension damping & $30 \mathrm{~s}^{-1}$ \\
\hline$\mu / \mathrm{Ms}=$ unsprung mass & 0.150 \\
\hline $\mathrm{Kt} / \mathrm{Ms}=$ tyre stiffness & $400 \mathrm{~s}^{-2}$ \\
\hline $\mathrm{B}=$ tyre enveloping (base length) & $250 \mathrm{~mm}$ \\
\hline Initialisation Distance & $19 \mathrm{~m}$ \\
\hline
\end{tabular}

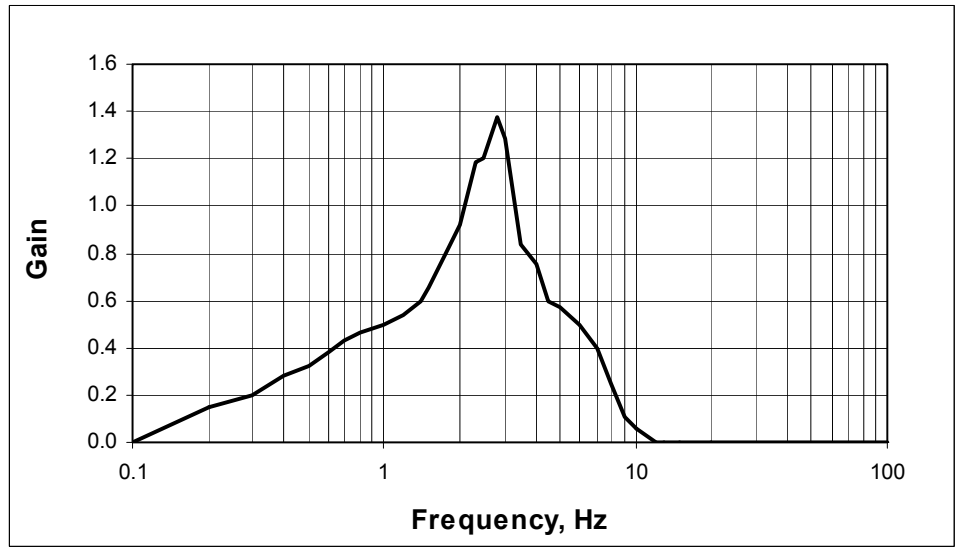

Figure 1: HATI frequency response function.

HATI is calculated by accumulating the vertical response of heavy vehicle body to road input. It captures the effects of the low frequency vertical and translational modes such as body bounce and pitch due to its sensitivity to the long roughness wavelengths. Determining HATI values involves the following steps:

1. Using RoadRuf shareware, Sayers and Karamihas [9], the surface profile data is converted to slope and then filtered using the quarter car model, used for calculating the IRI, but with the specific set of coefficients defined for HATI QTM (table 1). The simulated response denoted the Profile Index (PI) is accumulated using an exponent of 2 for root mean square (RMS) slope.

2. HATI is determined as the average of PI values of the outer (OT) and inner (IN) wheel paths and calculated using eqn. (1). HATI has units of slope, $\mathrm{mm} / \mathrm{m}$ or $\mathrm{m} / \mathrm{km}$.

$$
\mathrm{HATI}=\sqrt{\frac{\mathrm{PI}^{2}{ }_{\mathrm{OT}}+\mathrm{PI}^{2}{ }_{\mathrm{IN}}}{2}}
$$




\subsection{Development of HATI}

HATI was developed using a subjective rating survey for 27 sections from State highways in Victoria/Australia. The sections were selected from two major freight routes, ranged in length between $200 \mathrm{~m}$ and $1000 \mathrm{~m}$ and covered different levels of roughness ranging between 1.11 and $4.24 \mathrm{~m} / \mathrm{km}$ IRI. All sections were made of granular pavements with sprayed seal overlying expansive subgrade soils but with different reactivity levels and located within different climatic regions. They have straight and flat alignments and situated in $100 \mathrm{~km} / \mathrm{hr}$ speed zones.

The ride quality of each section was rated by a panel of 10-15 heavy vehicle drivers during their normal transport operations. The rating scale used in the subjective assessment survey ranged between zero (0) for extremely poor to 5 for perfect. A rating between 0 and 1 corresponds to a very poor ride, 1-2 for poor ride, 2-3 for fair ride, 3-4 for good ride and 4-5 for very good ride. The test vehicles consisted of prime-mover semi-trailer combination units with different properties (suspension system, cabin configuration, and age). The effects of vehicle properties on drivers' ratings were tested using ANOVA and found to be not significant for the test data, Hassan [3].

Mean panel ratings (MPR) for the test sections were then determined and correlated with different profile-based roughness indices. The latter were determined by applying different types of filters, covering different roughness wavebands and weighting functions. The results showed that MPR correlates best with roughness indices covering the longer wavelengths of the roughness spectrum with HATI QTM yielding the highest coefficient of correlation. Correlation coefficients between HATI and IRI with MPR were -0.91 and -0.82 respectively. An exponential statistical transform denoted Truck Ride Number $\left(\mathrm{TRN}_{\mathrm{HATI}}\right.$ ) that predicts MPR from the profile index HATI (in $\mathrm{mm} / \mathrm{m}$ ) was developed and has the form shown in eqn. (2) and a coefficient of determination $\left(\mathrm{r}^{2}\right)$ of 0.90 . HATI can predict MPR with an accuracy of \pm 0.3 at $95 \%$ confidence.

$$
T R N_{\text {HATI }}=5 e^{-255 H A T I^{0.92}}
$$

The IRI is a measure of vehicle's body vertical vibrations/displacements with high sensitivity (gain $>1$ ) at frequencies $1-12.5 \mathrm{~Hz}$. In other words, it can capture most of the low frequency vibration modes at which the truck body is most responsive, which explains the good correlation with MPR. However, HATI proved to be a better predictor of TRN/MPR than IRI. It can explain $90 \%$ of the variation in MPR whereas IRI can only explain $76 \%\left(\mathrm{r}^{2}=0.76\right)$ of the variation.

HATI values of the test sections and the corresponding MPRs were employed to develop a scale for HATI, table 2. The threshold for HATI between acceptable and unacceptable ride is 1.7 , which results in a $\mathrm{TRN}_{\mathrm{HATI}}<2.5$. However, a value of $2.2 \mathrm{~m} / \mathrm{km}$ is recommended for use as the maintenance intervention level. These values apply to heavy articulated vehicles travelling on State highways at $100 \mathrm{~km} / \mathrm{hr}$. HATI values at other speeds are different and, similar to the IRI, scales for the different speeds need to be developed. 
Table 2: $\quad$ HATI and $\mathrm{TRN}_{\mathrm{HATI}}$ scale.

\begin{tabular}{|c|c|c|}
\hline HATI $(\mathrm{m} / \mathrm{km})$ & Perception & TRN $_{\text {HATI }}$ Scale \\
\hline$<0.5$ & Very Good & $4-5$ \\
\hline $0.5-1.20$ & Good & $3-4$ \\
\hline $1.20-2.20$ & Fair & $2-3$ \\
\hline $2.20-4.0$ & Poor & $1-2$ \\
\hline$>4.0$ & Very Poor & $0-1$ \\
\hline
\end{tabular}

\section{Effect of soil reactivity}

The rating sections are located in expansive soil areas but with different reactivity levels and lie within different climatic conditions. Expansive soils have the potential for shrinking or swelling under changing moisture conditions. Movement in expansive soils usually occurs in an uneven pattern resulting in distortion of the longitudinal profile of the pavement surface and the development of long wavelength roughness (LWR). Climate and soil reactivity influence the extent of LWR development and ultimately HATI values. HATI QTM is only sensitive to excitation by LWR $>3 \mathrm{~m}$. The highest gain $(>0.9)$ occurs in the frequency range 2-3.5 Hz, which can be excited by roughness wavelengths $8-14 \mathrm{~m}$ when travelling at $100 \mathrm{~km} / \mathrm{hr}$. The wavelength equals the speed (length per second) divided by the frequency (cycles per second).

Examination of the spectral properties of the sections from the two State highways indicated that Princes Highway west (PW) sections are associated with higher contents of LWR (low wavenumbers, wavenumber is the inverse of wavelength) than Princes Highway east (PE) sections. PW sections are founded on highly reactive subsoil and lie within a problematic climate zone whereas, PE sections overlie subsoil of lower reactivity and lie within a climate zone that is less prone to having problems. Fig. 2 presents a comparison between the spectral properties in the outer wheel paths of two test sections with similar high IRI values, $(P E, I R I=3.80 \mathrm{~m} / \mathrm{km}$ vs $P W, I R I=3.73 \mathrm{~m} / \mathrm{km}$ ).

Fig. 3 shows the variations in HATI values and the corresponding MPR values of the sections from the two highways with similar IRI values. It can be observed that, generally, PW sections have higher HATI values than PE sections, which resulted in PW sections being rated lower than PE sections with same IRI values. These results are expected considering the reactivity of the subsoil and the effect of climate.

\section{Validation of HATI}

The effectiveness of HATI in highlighting sections with poor ride quality for heavy transport operators and its applicability to other regions was validated using two data sets, Hassan et al. [8]. The data sets included sections from different State highways in rural Victoria and from a State highway in New Zealand that were identified by drivers of heavy articulated vehicles to have poor 


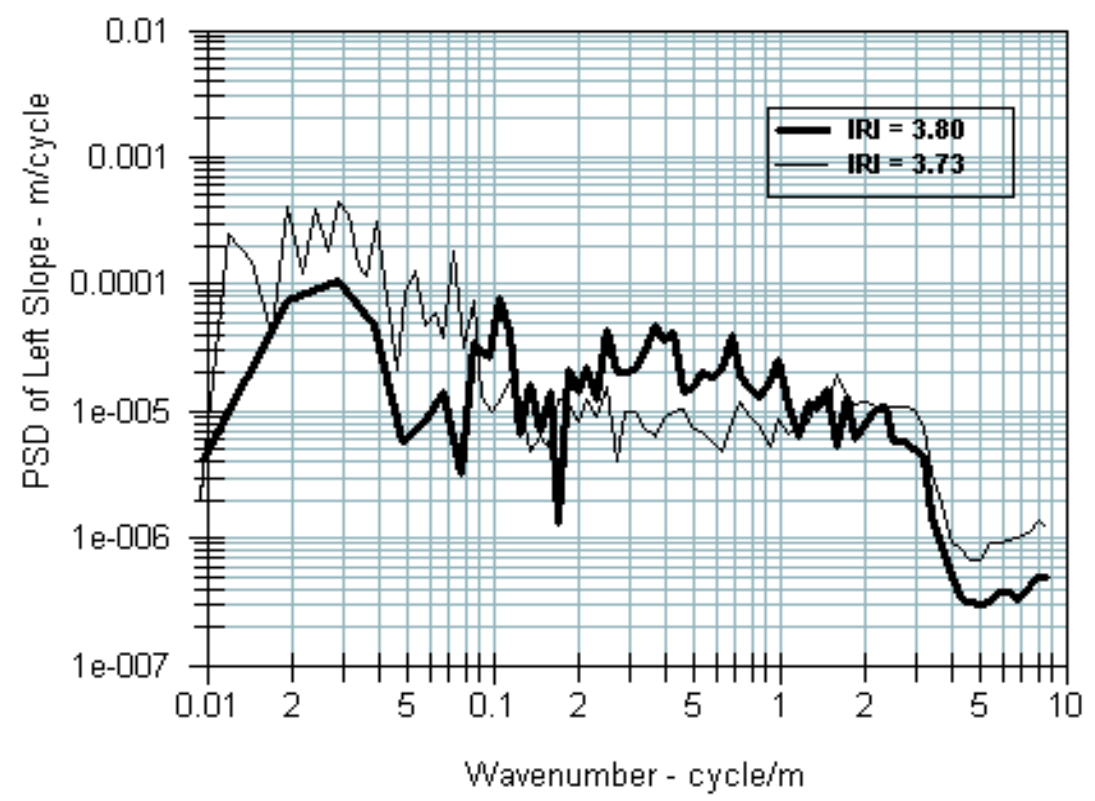

Figure 2: $\quad$ PSDs of profile slope of the outer wheel path for sections with similar high IRIs.

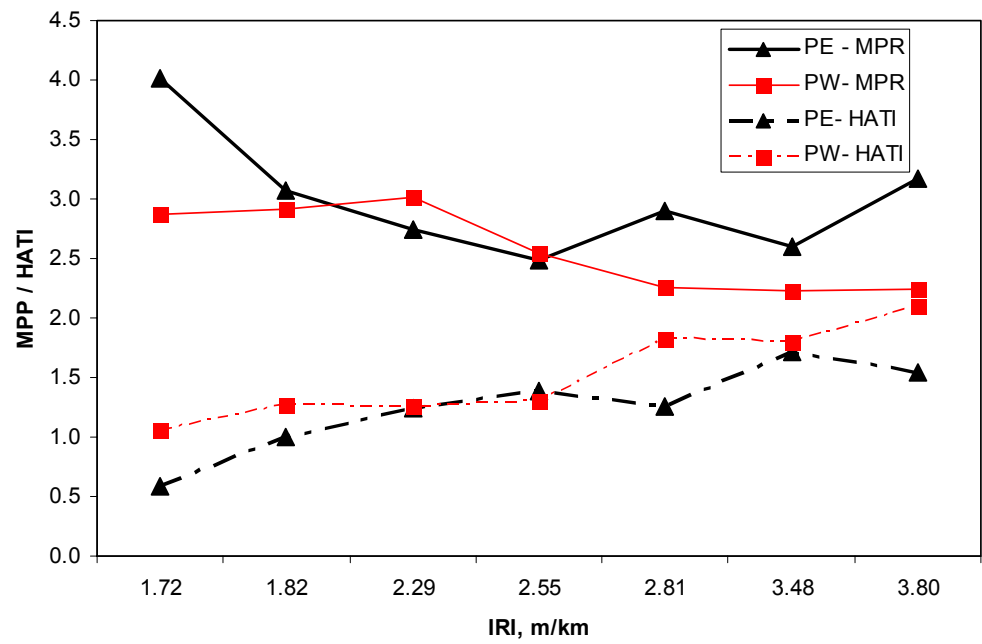

Figure 3: $\quad$ Effect of section location (PE vs PW).

ride quality. For the NZ sections, sediments (non-expansive) make up the subgrade soil. The validation results proved that HATI is effective in highlighting the candidate sections from both data sets. The results of this assessment indicated that HATI is effective in highlighting sections with poor 
ride quality in different regions and climatic conditions, where the ground is subject to settlement or differential movement. These conditions result in developing high contents of LWR (3-20m) in the pavement surface. The effects of LWR on ride cannot be eliminated by vehicle design but by road works.

\section{HATI as a predictor of dynamic wheel loads}

The interaction between road surface roughness and heavy vehicle body results in dynamic wheel loading (DWL), which increases pavement damage. The magnitude of these loads is dependent on surface roughness level and characteristics in addition to other factors such as speed and heavy vehicle properties. When travelling at normal highway speeds, roughness wavelengths within the frequency band to which HATI QTM is sensitive, excite the low frequency vibration modes of heavy vehicle body such as body bounce and pitch modes. As these modes are considered to be the major contributors to dynamic wheel loading [5, 10, 11], it was hypothesised that HATI could be a good predictor of the magnitude of the DWL and associated pavement damage.

To investigate the effectiveness of HATI in highlighting sections subject to high DWL, thirty-two $100 \mathrm{~m}$ sections were selected from three freight routes in rural Victoria/Australia. They are located in expansive soil areas with two reactivity levels (low and high), lie within different climatic regions and have different IRI values. Computer simulations were carried out on the profile data of these sections using a full vehicle model to measure the DWL associated with the drive and trailer axle groups. These dynamic wheel forces were reduced to a simple parameter known as the Dynamic Load Coefficient (DLC), Sweatman [12]. The vehicle model used in the simulation is a prime-mover semi-trailer combination unit with tandem drive and trailer axles, both fitted with airbag suspensions.

The DLC value for each section was determined by averaging the DLC values of the two axle groups in both wheel paths. Fig. 4 shows the DLC and HATI values for test sections with similar IRI values. The figure clearly indicates that, generally, sections with higher HATI values are associated with higher DLC values. It also indicates that sections in high reactivity region (high) are associated with higher DLC values than those in low reactivity region (low) as they have higher HATI values.

The DLC average values for the test sections were correlated with relevant HATI and IRI values. The correlation coefficients are presented in table 3 for all sections combined, and when grouped by soil reactivity level. These results indicate that both HATI and IRI are good indicators of pavement sections subject to high DWL in regions with low subsoil reactivity with HATI being a better predictor of pavement damage represented by the DLC. HATI can explain $90 \%$ of the variation in DLC, whereas IRI can explain $85 \%$ only. Both models were found to be significant at $95 \%$ confidence level. On the other hand, both HATI and IRI proved to be poor indicators of the dynamic behaviour of road pavements founded on expansive soils with high reactivity. 


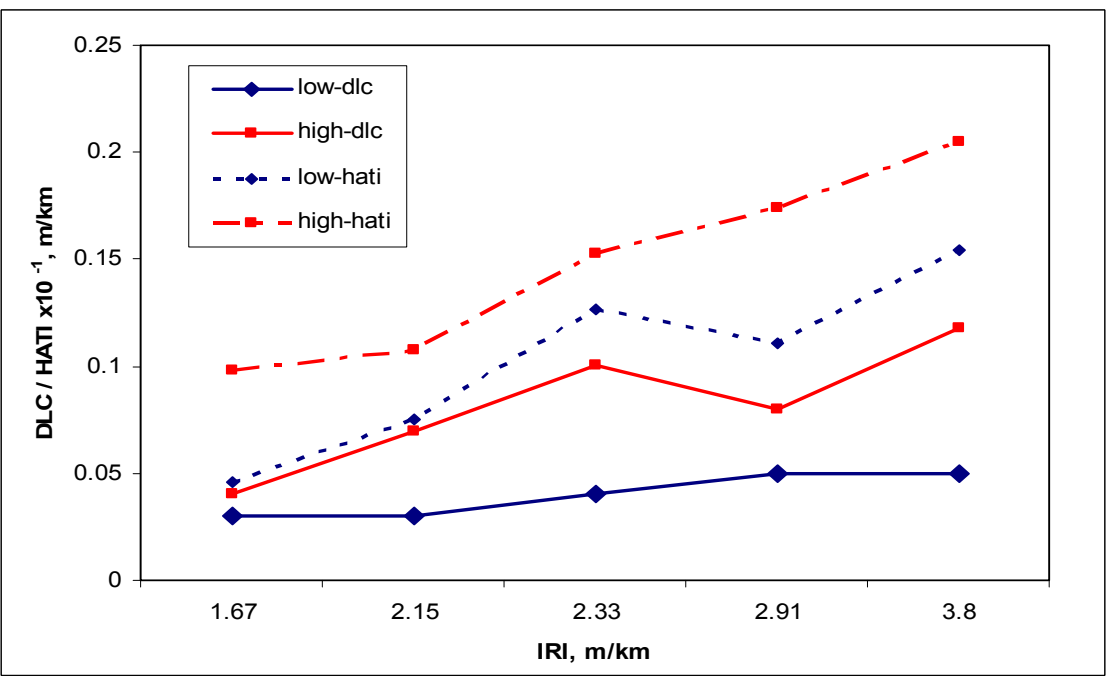

Figure 4: $\quad$ DLC and HATI values for sections with similar IRI values.

Table 3: $\quad$ Correlation results between HATI, IRI and the DLC.

\begin{tabular}{|c|c|c|c|}
\hline Variable & \multicolumn{3}{|c|}{ DLC } \\
\hline & All, $\mathrm{n}=31$ & Low, $\mathrm{n}=16$ & High, $\mathrm{n}=15$ \\
\hline IRI & 0.46 & 0.88 & 0.42 \\
\hline HATI & 0.60 & 0.92 & 0.46 \\
\hline$P I_{d w l}=\sqrt{P I_{b} r+P_{b} I b}$ & 0.81 & 0.93 & 0.88 \\
\hline$P I_{d w l}=\sqrt{P I_{b} r+P_{b} I b+P I_{b} a}$ & 0.71 & 0.94 & 0.69 \\
\hline
\end{tabular}

Further analysis was undertaken to test other profile-based indices as predictors of DLC. They included a number of 4-pole butterworth band pass filters in the wavebands of interest. The butterworth band-pass filter is defined by the short and long wavelengths where the filter gain is 0.707 . The output of the filter is reduced to yield RMS slope value called Profile Index $\left(\mathrm{PI}_{\mathrm{b}}\right)$. The $\mathrm{PI}_{\mathrm{b}}$ values of the two wheel paths are averaged using a similar formula to eqn (1). The wavebands tested covered the frequency bands where the peak forces were observed in the DWL spectra for all sections. They include $0.4-0.8 \mathrm{~Hz}\left(\mathrm{PI}_{\mathrm{b}} \mathrm{r}\right), 1.5-$ $4 \mathrm{~Hz}\left(\mathrm{PI}_{\mathrm{b}} \mathrm{b}\right)$ and $8-15 \mathrm{~Hz}\left(\mathrm{PI}_{\mathrm{b}} \mathrm{a}\right)$ which, correspond to excitations of the body roll, body bounce and pitch, and axle hop modes, respectively.

The DWL index, denoted $\mathrm{PI}_{\mathrm{dwl}}$, which is determined by taking the square root of the sum of roughness contents in two frequency bands represented by the RMS of $\mathrm{PI}_{\mathrm{b}} \mathrm{r}$ and $\mathrm{PI}_{\mathrm{b}} \mathrm{b}$ proved to be the best predictor for low $\left(\mathrm{r}^{2}=0.90\right.$, similar to HATI) and high $\left(\mathrm{r}^{2}=0.83\right)$ reactivity sections and for all sections $\left(\mathrm{r}^{2}=0.80\right)$, refer to table 3 . Adding roughness content in the frequency band of $\mathrm{PI}_{\mathrm{b}} \mathrm{a}$ 
improved the predictions $\left(\mathrm{r}^{2}=0.93\right)$ for low reactivity sections only. All these models were developed using power transformation and were found significant at $95 \%$ confidence level.

These results indicate that the contribution of the high frequency mode excitation (axle hop) to DWL is not significant on sections founded on subgrades with highly reactive soils and the reverse is true on sections with lower reactivity soils. However the contribution of the low frequency modes (body roll, bounce and pitch) excitation is significant for all the test sections considered herein. The profile characteristics of these sections particularly, the high reactivity sections, were examined carefully and it was identified that they are associated with high variations in profile elevation between the two wheel paths. This variation results in exciting the body roll motion, which occurs at very low frequencies (0.4$0.8 \mathrm{~Hz}$ ) for the simulation vehicle.

\section{Conclusions}

HATI proved to be more effective than IRI in highlighting sections with characteristics that affect heavy articulated vehicle ride. This is mainly due to its sensitivity to low frequency roughness in the longitudinal profile which is responsible for inducing vertical and longitudinal vibrations in the truck cabin. HATI also proved to be applicable to different regions and climatic conditions, where the ground is subject to settlement or differential movement. These conditions result in developing high contents of LWR in the pavement surface. Vicroads and other Australian SRAs have adopted HATI and included it in their Pavement Management Systems to trigger maintenance and rehabilitation programs to improve rideability for the freight industry.

The analysis also showed that climate and reactivity of the subgrade soil have great influence on roughness characteristics of pavement surfaces and their dynamic interaction with heavy vehicles. The analysis also showed that most of the contribution to DWL is attributable to excitations from the longer wavelengths of the spectrum and the variation in profile characteristics between the two wheel paths. HATI also proved to be a good predictor of pavement damage due to DWL for sections founded on low reactivity soils within climate zones that are not problematic. However, a new DWL index, denoted $\mathrm{PI}_{\mathrm{dwl}}$, proved to be a better predictor of DWL induced damage for pavements founded on low and high reactivity subsoils. The proposed DWL index however, requires validation and further simulation to test its applicability to representative fleet vehicles. The adoption of such index is beneficial to road authorities as it removes the need for using simulation programs in identifying road sections subject to high DWL.

\section{References}

[1] Austroads, A Road Profile Based Truck Ride Index (TRI), AP-R177/00, Austroads, Sydney, Australia, 2000. 
[2] Granlund, J., Ahlin, K., \& Lundström, R., Whole Body Vibration When Riding on Rough Roads, Vagverket Publication 2000:31E, Sweden, 2000.

[3] Hassan, R., Assessment of Road Roughness Effects on Heavy Vehicles on State Highways in Victoria/Australia, PhD thesis, Swinburne University of Technology, Melbourne, Australia, 2003.

[4] Jamison, N.J. \& Cenek, P., Validation of a Proposed Truck Rotational Response Model, Central Laboratories Report 02-529706.00, Opus International Consultants Limited, New Zealand, 2002.

[5] Papagiannakis A.T. \& Gujarathi M.S., Roughness Model Describing Heavy Vehicle-Pavement Interaction, Transportation Research Record 1501, pp. 50-59, 1995.

[6] International Standard ISO 2631-1, Mechanical vibration and shock Evaluation of human exposure to whole body vibration, Part 1 General Requirements, 2nd edition, International Organization for Standardisation, 1997.

[7] Sweatman, P. \& McFarlane, S., Investigation into the Specification of Heavy Trucks and Consequent Effects on Truck Dynamics and Drivers: Final Report, Federal Office of Road Safety, Australia, 2000.

[8] Hassan, R. McManus, K. \& Cossens I, Development of HATI - Heavy articulated truck index, Proceedings of the 22nd ARRB conference, Canberra, ARRB Group, Melbourne, Australia, 2006.

[9] Sayers, M.W. \& Karamihas, S.M., The Little Book of Profiling, The University of Michigan, Transportation Research Institute, USA, 1998.

[10] Cebon, D., Handbook of Vehicle Road Interaction, Swets \& Zeitlinger publishers, London, 1999.

[11] De Pont, J., Road Profile Characterisation, Transit New Zealand Research Report No. 29, 1994.

[12] Sweatman, P.F., A Study of the Dynamic Wheel Forces in Axle Group Suspensions of Heavy Vehicles, ARRB Special Report No. 27, 1983. 